\title{
Motivational interviewing is equivalent to more intensive treatment, superior to placebo, and will be tested more widely
}

Burke BL, Arkowitz H, Menchola M. The efficacy of motivational interviewing: a meta-analysis of controlled clinical trials. J Consult Clin Psychol 2003;71:843-61.

Q How effective are adaptations of motivational interviewing for changing problem behaviours?

\section{METHODS}

$+$

Design: Systematic review with meta-analysis.

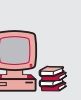

Data sources: PsycINFO (search date not stated), reference lists of three previous reviews, motivational interviewing website (www.motivationalinterview.org), discussion with motivational interviewing trainers.

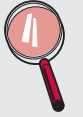

Study selection and analysis: Controlled clinical trials were included if the intervention used was based on motivational interviewing principles, was conducted individually and face to face, and used appropriate outcome measures. Effect sizes were calculated using Cohen's d measure.

Outcomes: Effect sizes, combined effect sizes for individual problem areas, longevity of treatment effect, and social impact of treatment.

\section{MAIN RESULTS}

Thirty studies met the inclusion criteria (15 targeted alcohol problems, five drug addiction, four diet and exercise habits, two smoking, two HIV risk behaviour, one treatment adherence, and one eating disorders), 11 of which found a statistically significant effect size favouring motivational interviewing. Motivational interviewing was significantly more effective than placebo or no treatment for alcohol or drug abuse, and diet and exercise problems, but not for

Table Effect sizes for motivational interviewing according to target behaviour (95\% confidence intervals)

\begin{tabular}{lll}
\hline & $\begin{array}{l}\text { Motivational } \\
\text { interviewing } v \text { placebo } \\
\text { or no treatment }\end{array}$ & $\begin{array}{l}\text { Motivational } \\
\text { interviewing } v \text { active } \\
\text { treatments }\end{array}$ \\
\hline $\begin{array}{l}\text { Alcohol abuse } \\
\text { Blood alcohol } \\
\text { concentration }\end{array}$ & $0.53(0.20$ to 0.86$)$ & - \\
$\begin{array}{l}\text { Standard ethanol } \\
\text { content }\end{array}$ & $0.25(0.13$ to 0.37$)$ & $0.09(-0.04$ to 0.23$)$ \\
$\begin{array}{l}\text { Drug abuse } \\
\begin{array}{l}\text { Diet and exercise } \\
\text { habits }\end{array}\end{array}$ & $0.56(0.31$ to 0.82$)$ & $-0.01(-0.25$ to 0.25$)$ \\
$\begin{array}{l}\text { Smoking } \\
\text { HIV risk }\end{array}$ & $0.11(-0.32$ to 0.62$)$ & - \\
\hline
\end{tabular}

For correspondence B Burke Department of Psychology, Fort Lewis Cöllege Durango, Colorado, USA; burke-b@fortlewis.edu

Sources of funding: not specified. smoking or HIV risk behaviour (see table). Motivational interviewing was not significantly better than other active psychotherapeutic treatments for alcohol or drug abuse (see table).

\section{CONCLUSIONS}

Motivational interviewing gave moderate effects when compared with placebo or no treatment for alcohol and drug abuse, and problems with diet and exercise. Motivational interviewing was as effective as other psychotherapeutic treatments for alcohol or drug abuse, but had no significant effect on smoking or HIV risk behaviour.

\section{Commentary}

D oes motivational interviewing present dilemmas for the evidencebased mental health practitioner? Motivational interviewing (MI) is an approach rooted in the Rogerian tradition specifically concerned with the exploration and resolution of ambivalence. ${ }^{1}$ It was originally developed as a helpful way to talk to those with drinking problems, and involves elements of directiveness in giving structure and focus to dialogue. It has now been applied to a wide array of health problems, showing considerable promise both as brief treatment and for prevention. The accumulation of evidence for applications has now resulted in this first meta-analysis, which provides a compelling and authoritative evaluation of the existing research literature. This evidence base will expand rapidly with many more trials currently in progress than have been reported to date.

$\mathrm{Ml}$ is a potentially helpful means of avoiding unproductive confrontations about behaviour and change. Brief applications may be offered as interventions in their own right or by way of preparation for other treatments. Research on dedicated adaptations to the most common mental health problems, however, is currently at a relatively early stage of development compared with applications in the original field of addiction. Careful attention on the part of the evidence-based practitioner to the evolving research literature, including intervention development studies of new adaptations, is thus to be encouraged. This will require attention to evidence beyond that which emerges from trials.

One recent finding is the importance of the quality rather than the quantity of client speech relating to commitment to change, ${ }^{2}$ underlining the specific importance of listening very carefully to clients, and more generally to the construction of an atmosphere of meaningful exchange. Careful eliciting of the values, assumptions, fears, and hopes of the patient is fundamental to both $\mathrm{MI}$ and to evidence-based mental health practice, as is skilful interpretation and application of evidence in the interests of the client. ${ }^{3}$

Jim McCambridge Wellcome Trust Health Services Research Fellow, National Addiction Centre, London, UK

1 Miller WR, Rollnick S. Motivational interviewing: preparing people for change, 2nd ed. New York: Guilford Press, 2002

2 Amrhein PC, Miller WR, Yahne CE, et al. Client commitment language during motivational interviewing predicts drug use outcomes. J Consult Clin Psychol 2003;71:862-78

3 Szatmari P. The art of evidence-based child psychiatry. Evid Based Ment Health 2003:6:99-100. 